\title{
Synthesis and characterization of gold nanorods and their application for photothermal cell damage
}

\author{
Mohd Samim ' \\ CK Prashant ${ }^{2}$ \\ AK Dinda ${ }^{2}$ \\ AN Maitra ${ }^{3}$ \\ Indu Arora ${ }^{4}$ \\ 'Department of Chemistry, Hamdard \\ University, Hamdard Nagar, \\ New Delhi, ${ }^{2}$ Department of Pathology, \\ All India Institute of Medical \\ Sciences, New Delhi, ${ }^{3}$ Department \\ of Chemistry, University of Delhi, \\ Delhi, ${ }^{4}$ Department of Biomedical \\ Sciences, Shaeed Rajguru College \\ of Applied Sciences, University of Delhi, \\ Delhi, India
}

This article was published in the following Dove Press journal:

International Journal of Nanomedicine

16 September 2011

Number of times this article has been viewed

Background: Gold nanorods show a surface plasmon resonance (SPR) band at the near infra-red (NIR) region which enables them to produce heat on irradiation with a NIR laser. As a result of this, gold nanorods have the potential to be used as thermal therapeutic agents for selective damage to cancer cells, bacterial cells, viruses, and DNA.

Methods: Gold nanorods with an aspect ratio of approximately 5 were prepared by exploiting the normal micellar route of a water/dioctyl sulfosuccinate (Aerosol-T)/hexane system. The shape and size of the gold nanorods were characterized by surface plasmon bands at $520 \mathrm{~nm}$ and $980 \mathrm{~nm}$, and by atomic force microscopy and transmission electron microscopy.

Results: The length of the gold nanorods was $100 \mathrm{~nm}$ and their diameter was $20 \mathrm{~nm}$. X-ray diffraction analysis demonstrated that the gold nanorods formed were metallic in nature. The gold nanorods showed good photothermolysis activity.

Conclusion: Gold nanorods injected subcutaneously and irradiated with $980 \mathrm{~nm}$ laser caused injury to rat tissue, demonstrating that gold nanorods may be used to kill cancerous cells in tumor tissue.

Keywords: nanorods, gold, micellar system, photothermolysis

\section{Introduction}

Thermal therapeutics have several advantages over conventional techniques, being minimally invasive and relatively simple to perform, and having the potential to treat tumors embedded in vital regions where surgical resection is not feasible. ${ }^{1}$ Simple heating techniques have severe limitations in discriminating between tumor and surrounding healthy tissue, and often heat tissues between the source and the target site. Photothermal therapy using gold nanorods irradiated with near-infrared laser can damage cells and has great potential to cause selective damage to cancer cells, ${ }^{2}$ bacterial cells, ${ }^{3,4}$ viruses, ${ }^{4,5}$ and DNA., ${ }^{4,5}$ On irradiation by near-infrared laser, gold nanorods warm up very quickly and reach a threshold temperature with a nonlinear effect, leading to irreparable target damage. ${ }^{1}$ With the burst of research activity in the area of nanomedicine, a variety of nanostructures with special optical properties have been developed rapidly, and have biomedical applications. ${ }^{6-13}$ Noble metal nanoparticles have emerged as powerful photothermal therapy agents in the field of cancer therapeutics, because they have enhanced cross-sectional absorption, which is four to five times greater than that of conventional photoabsorbing dyes. As a result, effective laser therapy is carried out at relatively lower energies, rendering the therapy minimally invasive. Moreover, metal nanoparticles are very photostable and therefore
Correspondence: Mohd Samim

Department of Chemistry, Hamdard

University, Hamdard Nagar, New Delhi

I I0062, India

Tel +9l 01126059688

Email shamim_chem@yahoo.co.in 
less prone to photobleaching. Nowadays, gold nanorods, ${ }^{14-17}$ gold nanospheres, ${ }^{18,19}$ and nanoshells ${ }^{20-23}$ are showing promise in the field of photothermal therapy because of their ease of preparation, ready multifunctionalization, and tunable optical properties. Using deep-penetrating near-infrared laser, several groups have investigated the treatment of cancer by hyperthermia. In this paper, we describe novel laser-induced thermal therapy using gold nanorods. Depending upon their aspect ratio, nanorods absorb or scatter light at desired wavelengths across the visible and near-infrared regions. ${ }^{24}$ In this experiment, we used gold nanorods to produce radiation at the near-infrared region of $980 \mathrm{~nm}$ instead of at $520 \mathrm{~nm}$, as commonly used for ultrafine gold nanospheres.

\section{Materials and methods Materials}

The chemicals used in this study, including auric chloride, hexane, absolute alcohol, and hydrazine hydrate, were purchased from Spectrochem Ltd (New Delhi, India), and dioctyl sulfosuccinate sodium salt (AOT) was purchased from ACROS Organics (Fair Lawn, NJ). These reagents were used without further purification.

\section{Synthesis of gold nanorods}

The gold nanorods were prepared in an AOT/water/hexane reverse system by reduction of gold chloride with hydrazine hydrate. At increased concentrations of AOT, the spherical reverse micellar droplets gradually became distorted and took on a needle-shaped structure. The aqueous needleshaped core could be used as a template for synthesis of gold nanorods. In a typical set, $100 \mu \mathrm{L}$ of $2 \% \mathrm{w} / \mathrm{v}$ gold chloride was added to $10 \mathrm{~mL}$ of AOT $1 \mathrm{M}$ in hexane. The solution was stirred for 30-40 minutes until an optically clear reverse micellar solution was obtained. A calculated amount of water $(1700 \mu \mathrm{L})$ was added to maintain the desired $W_{0}$, ie, the molar ratio of water to oil. The mixture was stirred until a transparent microemulsion solution was obtained. In a similar set of AOT $1 \mathrm{M}$ samples in hexane, $100 \mu \mathrm{L}$ of hydrazine (prepared by mixing $5 \mu \mathrm{L}$ of pure hydrazine and $995 \mu \mathrm{L}$ water) was added. The solution was stirred for 30-40 minutes until an optically clear micellar solution was obtained. After preparation of the above two micelle solutions, they were mixed by dropwise addition of the latter to the former solution with constant stirring. The color of the solution changed gradually from yellow to black, indicating the formation of gold nanorods. The solution was then stirred for another 2 hours. After stirring, ethanol 4-5 mL was added to the solution, which was stirred again for
1 minute, and hexane 6-7 mL was then added, with further stirring for 1 minute. The solution became turbid and was left undisturbed for 2 hours. This resulted in the formation of two phases, and black-colored particles separated out at the interface of the phases. We micropipetted these particles into an Eppendorf tube and centrifuged them for 2 minutes at $7000 \mathrm{rpm}$. The pellet of particles formed at the bottom of the tube was collected after discarding the supernatant. Hexane $1 \mathrm{~mL}$ was added to the pellet and the sample was sonicated until the particles became dispersed. After dispersion, the sample was centrifuged for 2 minutes at $7000 \mathrm{rpm}$. This step was repeated five times to wash away the surfactant.

\section{Physicochemical characterization of gold nanorods \\ Optical properties using absorption spectroscopy in visible region}

All spectrophotometric studies were carried out using a UV-1600 ultraviolet-visible spectrophotometer (Shimadzu, Kyoto, Japan). One milligram of gold nanorods was dispersed in $1 \mathrm{~mL}$ of distilled $\mathrm{H}_{2} \mathrm{O}$ and the solution was thoroughly sonicated for half an hour. The spectrum was taken by using simple $\mathrm{H}_{2} \mathrm{O}$ as the reference.

\section{Determination of crystallographic structure by X-ray diffraction}

To determine the crystallographic nature of the gold nanorods, electron diffraction and X-ray diffraction experiments were performed on a Bruker AXS D8 diffractometer using pressed pellets as samples with Ka radiation (11/4 1:5418 p). The $\mathrm{X}$-ray source used was $\mathrm{Cu}-\mathrm{K} \alpha$ radiation at $40 \mathrm{kV}$ and $20 \mathrm{~mA}$, and diffraction was analyzed using a PW 3710 diffractometer (Philips, Amsterdam, the Netherlands), with $0.2 \mathrm{~g}$ of lyophilized nanoparticles placed inside the diffractometer for analysis. X-ray diffraction could provide structural information for a large portion of the sample, whereas transmission electron diffraction could provide structural information for selected areas of the sample.

\section{Size and morphology using transmission electron microscopy}

Transmission electron microscopy (TEM) measurements were performed using a JEOL Model JEM (JEOL USA Inc, Peabody, MA) 200-2000× electron microscope operated at an accelerating voltage of $120 \mathrm{kV}$. Samples were prepared by placing small drops of dispersed gold nanorods (lyophilized powder) into water on formvar-coated copper grids and allowing the solvent to evaporate slowly at room temperature. The dried grid was then examined under an electron microscope. 
A

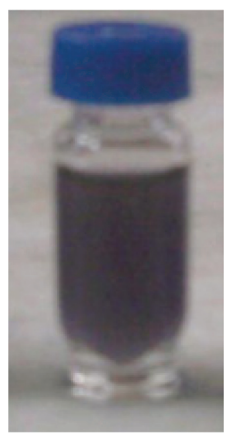

\section{B}

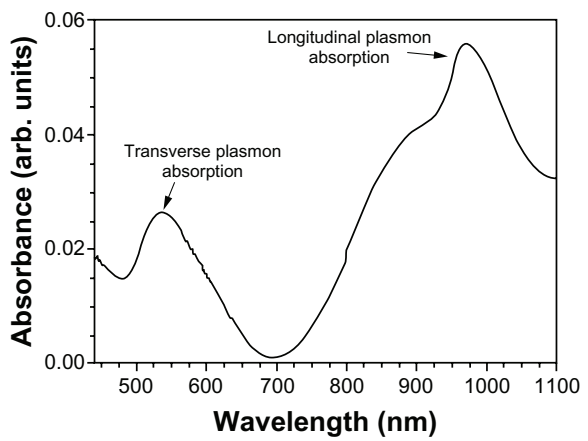

Figure I (A) Photograph of a microemulsion of nanorods in a sample bottle. (B) Absorbance spectra, with the transverse mode shows resonance at about $535 \mathrm{~nm}$, which is consistent with the plasmon band of spherical particles; the longitudinal mode shows resonance at about $980 \mathrm{~nm}$, corresponding to the plasmon band of the nanorod particle.

\section{Morphology using atomic force microscopy}

We carried out all atomic force microscopy (AFM) measurements using a Pico SPM (Molecular Imaging, Phoenix, AZ) operated in an acoustically driven, intermittent contact ("tapping") mode. We prepared samples for AFM by first diluting the test solutions by at least 100 -fold using deionized water. We then placed $5 \mu \mathrm{L}$ of the final solution directly onto the surface of a freshly cleaved mica disk. The sample was discarded if the solution did not spread evenly across the mica. The samples were dried in air, encased in covered Petri dishes at room temperature for at least 5 hours, and the AFM measurements of the number of features per unit area were found to be highly reproducible.

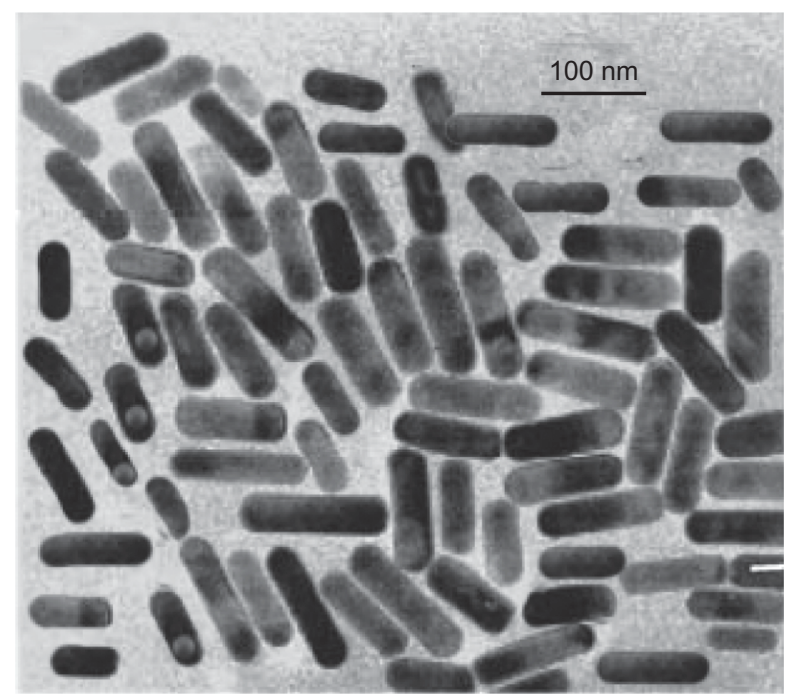

Figure 3 Rod-shaped morphology of gold nanorods.

\section{Application of gold nanorods in photothermal therapy \\ Photothermolysis}

Wistar rats aged 6-8 weeks were used in this study. The animals were maintained according to the guideline approved by the Institutional Animal Care and Use Committee. Three diseasefree rats were shaved clean and six spots of around $1.5 \mathrm{~cm}$ in diameter were marked dorsally (as shown in Figure 5). Four skin spots were painted with the gold nanorod dispersion and

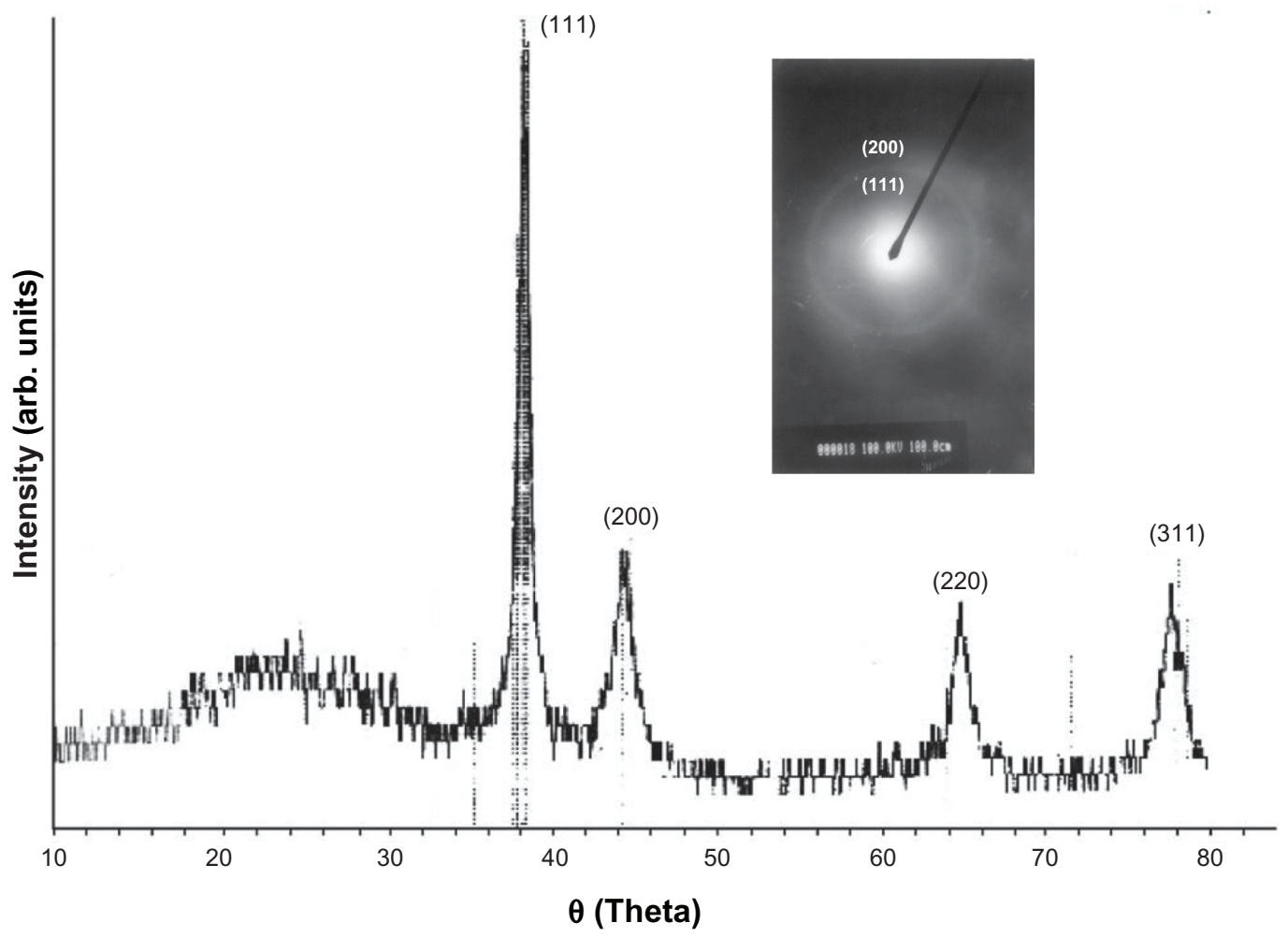

Figure 2 X-ray diffraction spectrum of gold nanorods. 


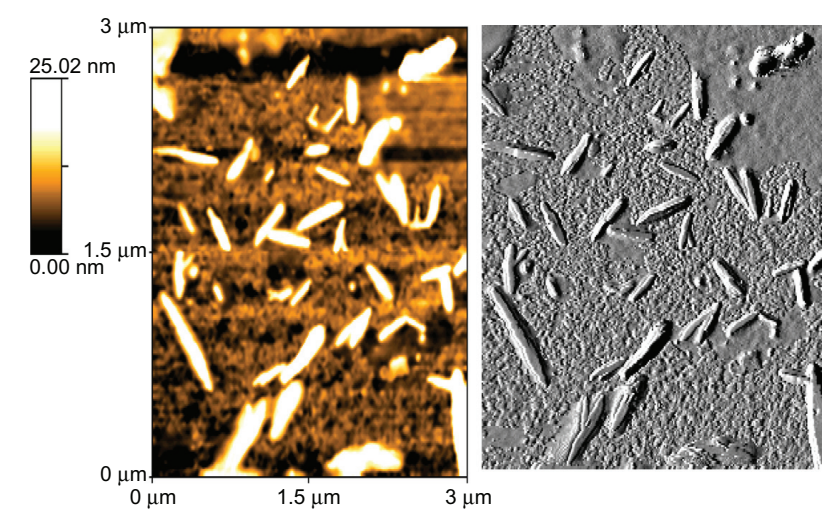

Figure 4 AFM photographs of gold nanorods.

one spot was injected with the gold nanorod dispersion. The particles were suspended in sterile double-distilled water $1 \mathrm{mg} / \mathrm{mL}$. The painted areas and the injected area were irradiated with an infrared-based laser beam of wavelength $980 \mathrm{~nm}$ and power $200 \mathrm{~mW}$. The irradiation times were 3, 5, 10, and 15 minutes for the painted spots; one spot was left unpainted and injected with saline solution as a control, while the sixth spot was injected with $300 \mu \mathrm{L}$ of gold nanorod dispersion solution. Both the control and intradermally injected spots were irradiated for 15 minutes. After the procedure, the rats were sacrificed, and the skin spots were dissected out and processed further for histological evaluation.
Sections stained with hematoxylin and eosin and of varying dimensions and thickness were cleared in xylene and mounted with dibutyl phthalate xylene using cover slips. The slides were then observed under an upright microscope (Eclipse 600; Nikon, Tokyo, Japan), and images were captured with a digital charged-coupled device camera (DP-71; Olympus, Tokyo, Japan) mounted on the microscope.

\section{Results and discussion}

Figures 6A and 6B represent the macroscopic and microscopic images, which do not show any evidence of necrosis or tissue damage in the nonpainted or noninjected skin spots.

Gross examination revealed bluish-black discoloration in the subcutaneous tissue below the skin flap as shown in Figure 6, which was restricted to the area of gold nanorod injection. Histological examination of the laser-exposed area showed coagulative necrosis of the skin and subcutaneous tissue, including the skin appendages. There was infiltration of inflammatory cells by neutrophils (Figure 6D).

The shape of the surfactant aggregate plays an important role in providing the template for the shape of the nanoparticles. Spherical gold nanoparticles of size 8-18 nm can be prepared in AOT $0.1 \mathrm{M}^{25,26}$ With the increased concentration of surfactant, the spherical shape is distorted and the aggregate becomes prolate-shaped.

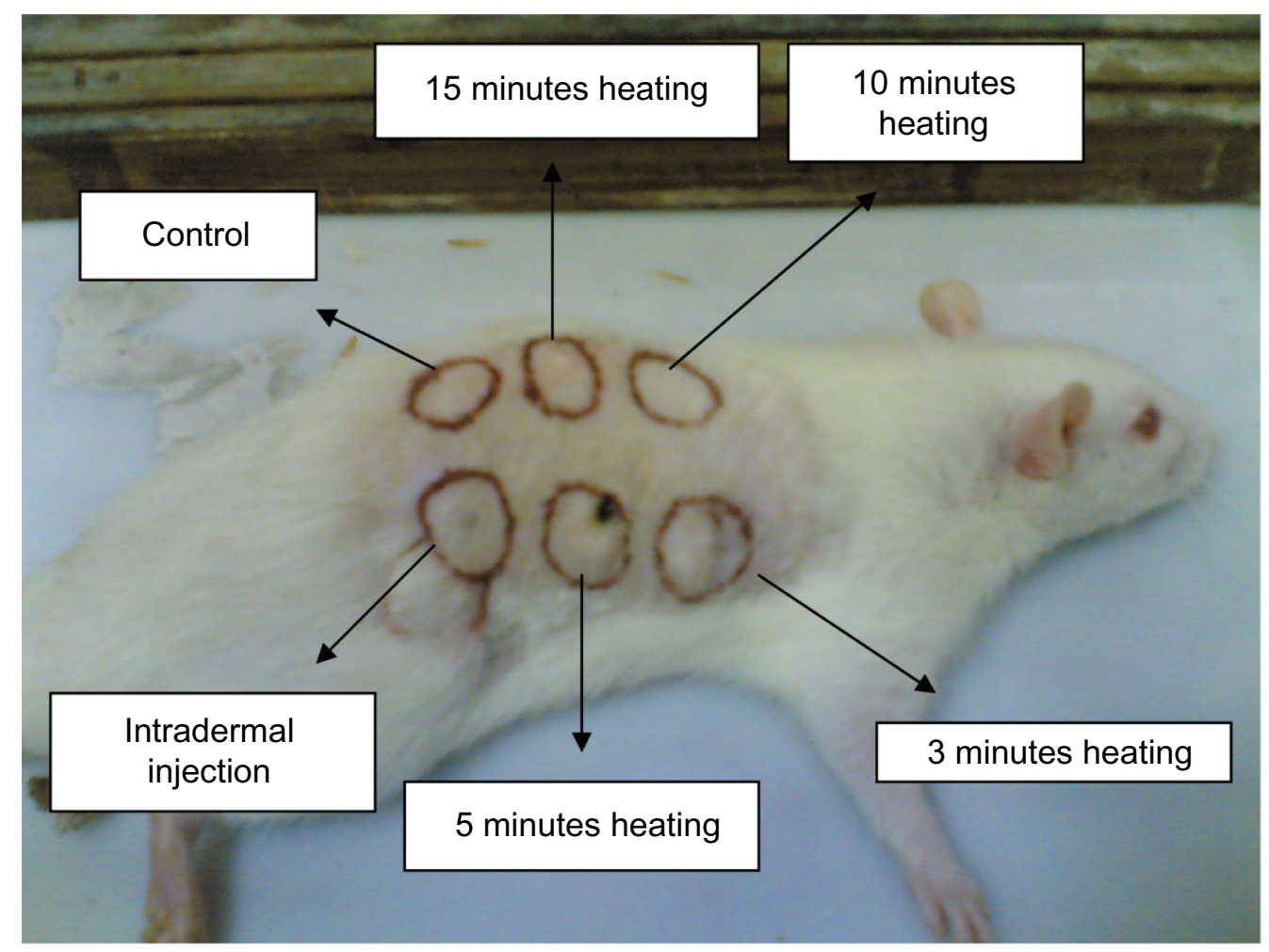

Figure $\mathbf{5}$ Six trial spots on rat dorsum. 
A

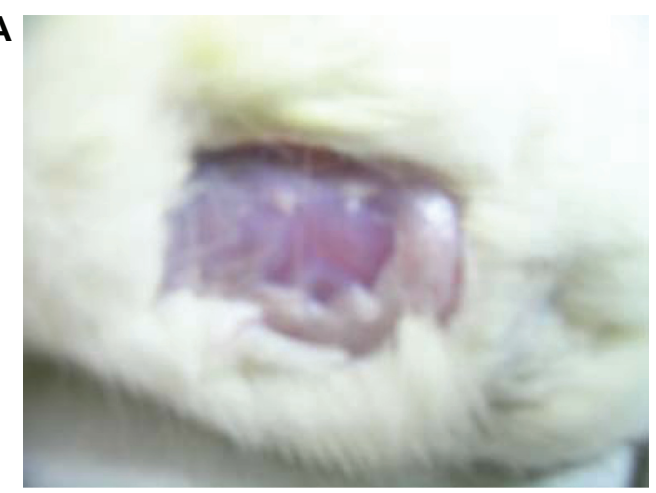

B

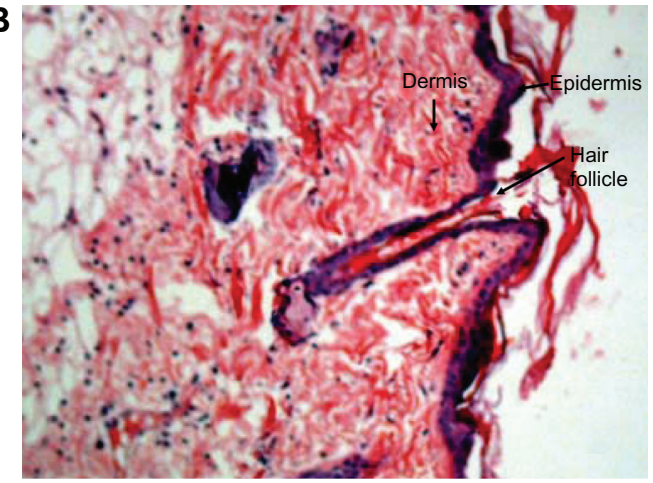

C

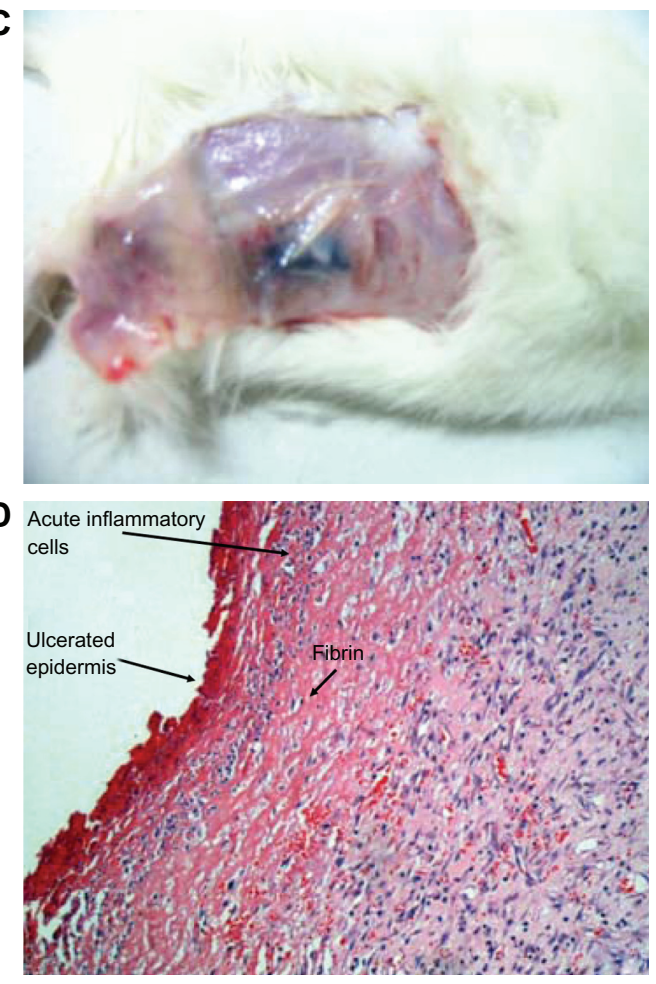

Figure 6 Histological photographs. (A, B) Gross and microscopic photographs of unpainted or uninjected spot on rat; (C, D) gross and microscopic photographs of painted or injected spot on rat.

Therefore, when the gold salt is reduced in AOT, rod-shaped gold nanoparticles are formed. ${ }^{27}$ We prepared gold nanorods of various aspect ratios using AOT concentrations of $0.5 \mathrm{M}$ to $1 \mathrm{M}$, and found that the nanorods formed had an aspect ratio of 5 at a $1 \mathrm{M}$ concentration of AOT and $\mathrm{W}_{\mathrm{o}}=10$. On dispersion in water, these nanorods had a strong absorption band at $980 \mathrm{~nm}$, so we adopted this protocol as standard for our all subsequent experiments. Colloidal dispersion of the metal showed absorption bands or broad regions of absorption in the ultraviolet-visible range. These are due to the excitation of plasmon resonance or interband transition, and are a characteristic property of the metallic nature of the particles. The absorption spectra for the gold nanorods were characterized by a dominant surface plasmon resonance band at a longer wavelength ${ }^{28}$ of $980 \mathrm{~nm}$, corresponding to longitudinal resonance, and a much weaker transverse resonance at a shorter wavelength of $535 \mathrm{~nm}$, as shown in Figure 1. Optical spectra clearly showed the formation of ultrafine gold nanorods. A representative TEM image and size distribution of a gold nanorod synthesized at a chloroplatinic acid concentration of $2 \%$ is shown in Figure 3. TEM micrographs of the gold nanorod particles obtained showed well-defined nanoscaling, with highly monodispersed, rod-shaped gold nanorods and a low polydispersity index. From the TEM image, it is apparent that the particle diameter is less than $20 \mathrm{~nm}$. The TEM images indicate the well-defined, rod-shaped morphology of the gold nanorods. Figure 4A shows a representative AFM image of a gold nanorod which also clearly indicates the rod-shaped morphology, and Figure 4B shows that the diameter is less than $20 \mathrm{~nm}$. A face-centered cubic close packing arrangement of the gold nanorods was evident from X-ray diffraction and selected diffraction studies of electrons in specific areas. Figure 2 shows the X-ray diffraction pattern for the gold nanorods. The peak positions are consistent with metallic gold ${ }^{28}$ Sharp peaks for gold are observed, which indicate the crystalline nature of the product. A strong peak at $2 \grave{\mathrm{e}}=38^{\circ}$ and $44^{\circ}$ corresponds exactly with a diffractogram of crystalline metallic gold reported previously. ${ }^{29}$ The inset in Figure 2 shows the selected area electron diffraction of these particles, which reveals only diffuse ring patterns, most probably attributable to the small particle size and polycrystalline nature of the particle core. Nevertheless, the diffraction features are consistent with the face-centered cubic crystalline structure of bulk metallic gold, with the two brightest rings corresponding to the diffraction planes of 111 and 200.

These particles were subsequently used as photothermolysis agents, to examine the feasibility of nanorod-assisted photothermal therapy. This technique takes advantage of the strong near-infrared absorption of nanorods, and a new class of gold nanoparticles with tunable optical properties that can undergo passive extravasation in tumor vasculature. Due to 
their nanoscale size, nanorods ( $<80 \mathrm{~nm}$ diameter) with peak optical absorption in the near-infrared range were injected subcutaneously or painted on six dorsal spots in three rats. Spots were then illuminated with a diode laser $(980 \mathrm{~nm}$, $200 \mathrm{~mW}$ ). All three treated rats had been healthy over the previous 24 hours. Following laser exposure, the animals were sacrificed, and the treated skin areas were examined macroscopically. Biopsies were then taken from the area and fixed in 10\% formalin for histological examination. Gross examination revealed bluish black discoloration of the subcutaneous tissue below the skin flap restricted to the area of injection of the gold nanorods. Histological examination of the laser-exposed area showed coagulative necrosis of the skin and subcutaneous tissue, including the skin appendages. In the shaven control rat tissue, $0.2 \mathrm{~mL}$ of normal saline was injected, and the area was exposed to laser for the same duration. The area was examined both macroscopically and microscopically, and no evidence of necrosis or tissue damage was found. Photomicrographs were taken of tissue sections stained with hematoxylin and eosin at a magnification of $200 \times$. This simple, noninvasive procedure shows great promise as a technique for selective photothermal tumor ablation.

\section{Conclusion}

This paper describes the preparation and characterization of gold nanorods by exploiting the normal micellar route of water/AOT/hexane. The shape and size of the gold nanorods were measured by AFM and TEM. The gold nanorods showed good photothermolytic activity. Gold nanorods injected subcutaneously and irradiated with $980 \mathrm{~nm}$ laser caused injury to rat tissue.

\section{Disclosure}

The authors report no conflicts of interest in this work.

\section{References}

1. Letfullin RR, Joenathan C, George TF, Zharov VP. Laser induced explosion of gold nanoparticles: Potential role for nanophotothermolysis of cancer. Nanomedicine. 2006;1:473-480.

2. Pitsillides CM, Joe EK, Wei X, Anderson RR, Lin CP. Selective cell targeting with light absorbing microparticles and nanoparticles. Biophys J. 2003;84:4023-4032.

3. Zharov VP, Galitovsly E, Viegas M. Photothermal guidance of selective photothermolysis with nanoparticles. Proc SPIE. 2004;5319: 291-300.

4. Zharov VP, Kim J-W, Everts M, Curiel DT. Self assembling nanoclusters in living systems: Application for integrated photothermal nanodiagnostics and therapy. J Nanomedicine. 2005;1:326-345.

5. Zharov VP, Kim J-W. Amplified laser nanoclusters interaction in DNA, viruses, bacteria, and cancer cells: Potential for nanodiagnostics and nanotherapy. Lasers Surg Med. 2006;Suppl 18:16-17.
6. El-Sayed MA. Some interesting properties of metals confined in time and nanometer space of different shapes. Acc Chem Res. 2001;34: 257-264.

7. Niemeyer CM. Nanoparticles, proteins, and nucleic acids: Biotechnology meets materials science. Angew Chem Int Ed Engl. 2001;40: 4128-4158.

8. Daniel MC, Astruc D. Gold nanoparticles: Assembly, supramolecular chemistry, quantum-size-related properties, and applications toward biology, catalysis, and nanotechnology. Chem Rev. 2004;104: 293-346.

9. West JL, Halas NJ. Engineered nanomaterials for biophotonics applications: Improving sensing, imaging, and therapeutics. Annu Rev Biomed Eng. 2003;5:285-292.

10. Xia Y, Halas NJ. Shape-controlled synthesis and surface plasmonic properties of metallic nanostructures. MRS Bull. 2005;30:338-348.

11. Warren CWC, Maxwell DJ, Gao X, Bailey RE, Han M, Nie S. Luminescent quantum dots for multiplexed biological detection and imaging. Curr Opin Biotechnol. 2002;13:40-46.

12. Parak WJ, Gerion D, Pellegrino T, et al. Biological applications of colloidal nanocrystals. Nanotechnology. 2003;14:R15-R27.

13. Katz E, Willner I. Integrated nanoparticle-biomolecule hybrid systems: Synthesis, properties, and applications. Angew Chem Int Ed. 2004;43: 6042-6108.

14. Huang X, El-Sayed IH, El-Sayed MA. Cancer cell imaging and photothermal therapy in the near-infrared region by using gold nanorods. J Am Chem Soc. 2006;128:2115-2120.

15. Takahashi H, Niidome T, Nariai A, Niidome Y, Yamada S. Gold nanorod-sensitized cell death: Microscopic observation of single living cells irradiated by pulsed near-infrared laser light in the presence of gold nanorods. Chem Lett. 2006;35:500-501.

16. Takahashi H, Niidome T, Nariai A, Niidome Y, Yamada S. Photothermal reshaping of gold nanorods prevents further cell death. Nanotechnology. 2006; 17:4431-4435.

17. HuffTB, Tong L, Zhao Y, Hansen MN, Cheng JX, Wei A. Hyperthermic effects of gold nanorods on tumor cells. Nanomedicine. 2007;2: 125-132.

18. El-Sayed IH, Huang X, El-Sayed MA. Selective laser photo-thermal therapy of epithelial carcinoma using anti-EGFR antibody conjugated gold nanoparticles. Cancer Lett. 2006;239:129-135.

19. Huang X, Jain PK, El-Sayed IH, El-Sayed MA. Determination of the minimum temperature required for selective photothermal destruction of cancer cells using immunotargeted gold nanoparticles. Photochem Photobiol. 2006;82:412-417.

20. Hirsch LR, Stafford RJ, Bankson JA, et al. Nanoshell-mediated near infrared thermal therapy of tumors under MR guidance. Proc Natl Acad Sci U S A. 2003;100:13549-13554.

21. Loo CH, Lin A, Hirsch LR, et al. Nanoshell-enabled photonics-based imaging and therapy of cancer. Tech Cancer Res Treat. 2004;3: 33-40.

22. O'Neal DP, Hirsch LR, Halas NJ, Payne JD, West JL. Photothermal tumor ablation in mice using near infrared absorbing nanoshells. Cancer Lett. 2004;209:171-176.

23. Loo C, Lowery A, Halas NJ, West JL, Drezek R. Immunotargeted nanoshells for integrated cancer imaging and therapy. Nano Lett. 2005;5: 709-711.

24. Zharov VP, Letfullin RR, Galitovskaya EN. Microbubbles-overlapping mode for laser killing of cancer cells with absorbing nanoparticle clusters. J Phys D Appl Phys. 2005;38:2571-2581.

25. Herrera DP, Resto O, Briano JG, Rinaldi C. Synthesis and agglomeration of gold nanoparticles in reverse micelles. Nanotechnology. 2005;16: S618.

26. Chiang Ch-L, Hsu M-B, Lai L-B. Control of nucleation and growth of gold nanoparticles in AOT/Span80/isooctane mixed reverse micelles. J Solid State Chem. 2004;177:3891-3895.

27. Pileni MP. The role of soft colloidal templates in controlling the size and shape of inorganic nanocrystals. Nat Mater. 2003;2:145-150. 
28. Shankar SS, Ahmad A, Parischa R, Sastry M. Bioreduction of chloroaurate ions by geranium leaves and its endophytic fungus yields gold nanoparticles of different shapes. J Mater Chem. 2003; 13:1822-1826.
29. Wang HW, Shieh CF, Chen HY, Shiu WC, Russo B, Cao G. Standing [111] gold nanotube to nanorod arrays via template growth. Nanotechnology. 2006;17:2689-2694.

International Journal of Nanomedicine

\section{Publish your work in this journal}

The International Journal of Nanomedicine is an international, peerreviewed journal focusing on the application of nanotechnology in diagnostics, therapeutics, and drug delivery systems throughou the biomedical field. This journal is indexed on PubMed Central, MedLine, CAS, SciSearch $\AA$, Current Contents ${ } /$ Clinical Medicine,
Journal Citation Reports/Science Edition, EMBase, Scopus and the Elsevier Bibliographic databases. The manuscript management system is completely online and includes a very quick and fair peer-review system, which is all easy to use. Visit http://www.dovepress.com/ testimonials.php to read real quotes from published authors.

Submit your manuscript here: http://www.dovepress.com/international-journal-of-nanomedicine-journal 